\title{
Can We Estimate the Recurrence of Epistaxis with Simple Blood Tests?
}

\author{
Mustafa Korkut ${ }^{1}$, Cihan Bedel ${ }^{1}$, Yusuf Karancı ${ }^{1}$, Murat Duyan ${ }^{1}$
}

${ }^{1}$ Health Science University Antalya Training and Research Hospital, Department of Emergency Medicine, Antalya, Turkey

\begin{abstract}
Objective: Epistaxis is often treated in the emergency department (ED) and is one of the causes of bleeding that can be successfully managed by physicians. This study aimed to investigate whether there is a relationship between recurrent epistaxis and simple blood parameters (the values of mean platelet volume (MPV) and red cell distribution width (RDW)).

Method: This retrospective case-control study was designed at a tier-three ED. The patients were chosen from among those who applied to the ED for epistaxis between 1 January 2018 and 31 December 2018. Demographic data, seasonal application frequency, complete blood count results and clinical findings were retrospectively reviewed on the hospital information record system. The patients were categorized into three groups of recurrent epistaxis, nonrecurrent epistaxis and healthy control groups.
\end{abstract}

Results: 143 epistaxis patients in total including recurrent $(n=73)$ and non-recurrent $(n=70)$ patients were enrolled in this study. The healthy control group was composed of 77 patients. The MPV value was significantly higher in the recurrent epistaxis group than in the nonrecurrent epistaxis group $(8.91 \pm 1.16,8.48 \pm 1.06, P=0.006$, respectively). In addition, the mean platelet and platecrit values were significantly higher in the non-recurrent epistaxis group than in the recurrent epistaxis group $(P=0.034, P=0.043$, respectively). The high RDW level was found to be statistically significant both in the recurrent and non-recurrent epistaxis groups than in the control group $(P<0.001)$. The logistic regression analysis concluded that the high MPV value increased epistaxis 1.367 times [OR: $1.367(0.952-1.963), P=0.028]$.

Conclusion: High MPV levels caused an increase in the bleeding tendency in the patients with recurrent epistaxis.

Keywords: recurrent epistaxis, mean platelet volume, emergency department

\section{Correspondence:}

Cihan Bedel

Address: Health Science University Antalya Training and Research Hospital, Kazım Karabekir Street postal zip code: 07100 , Muratpaşa, Antalya, Turkey

Email: cihanbedel@hotmail.com

Received: 28.01.2020,

Accepted: 02.03 .2020

https://doi.org/10.5799/jcei/7839

\section{INTRODUCTION}

It is estimated that about half of the general population will have a nosebleed at least once a year, and about $6 \%$ of them require medical care and consult to emergency rooms [1]. Applying to emergency department (ED) due to recurrent epistaxis is related to increased morbidity and high healthcare costs. However, it is not much clear which risk factors cause the case [2]. While it is reported that several localized (e.g. trauma, nasal foreign body, nasal steroid medication, nasal papilloma, allergic rhinitis, etc.) and systemic (e.g. hypertension, coagulopathies, hemorrhagic, metabolic and vascular diseases, etc.) conditions cause epistaxis but the cause of epistaxis is unknown in most cases. It was claimed that nasal colonization of Staphylococcus aureus stimulated inflammation and and increased recurrent epistaxis in the nasal septum [3].

Mean platelet volume (MPV) is a routine whole blood count parameter (CBC) associated with platelet activity used by all physicians. When the metabolic and enzymatic activity was evaluated with platelet size, it was shown that large platelets were more active than small platelets $[4,5]$. It has been also reported that increased MPV values are related to thrombotic conditions such as atherosclerosis, myocardial infarctus and embolism [6]. Red cell distribution width (RDW), is a routine $\mathrm{CBC}$ parameter 


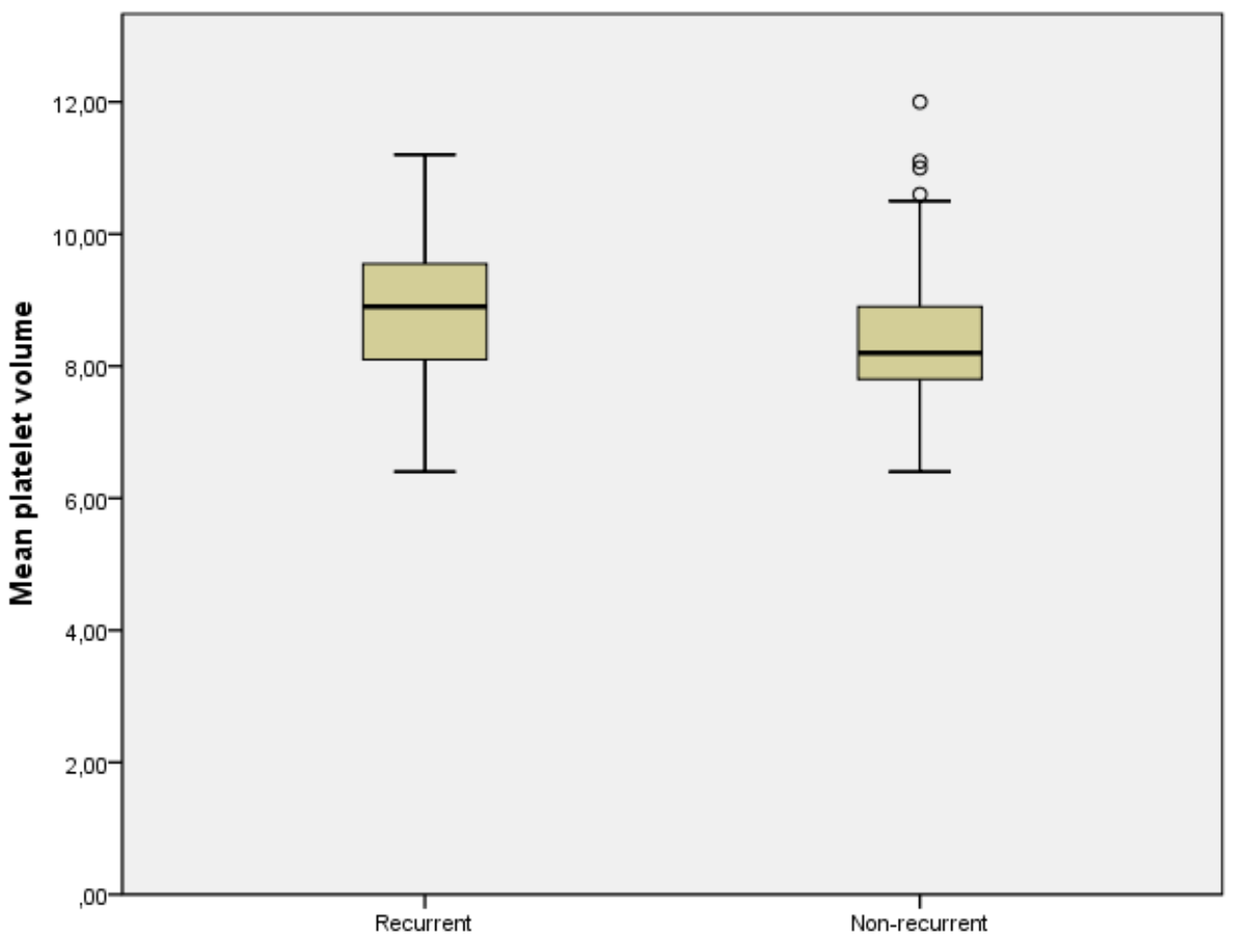

Figure 1. 2013 being adjacent to the intestinal wall, and approximately $35 \times 40 \mathrm{~mm}$ in size a thick-walled fluid-filled formation was detected

commonly used in the differential diagnosis of anemia, indicates the variation in erythrocyte population and RDW [7]. It has been reported that increased RDW values are in relation with coronary failure, myocarde infarctus, stroke, and malignancy [8-10].

We aimed to determine whether there is a relationship between recurrent epistaxis and simple blood parameters (MPV and RDW).

\section{METHODS}

This study was designed retrospectively and case control. The patients were chosen from among those who applied to a tier-three ED for epistaxis between 1 January 2018 and 31 December 2018. For this study ethics committee report was received. The patients who applied to the ED again with the same complaint within 15 days after the epistaxis were considered recurrent epistaxis patients. All the patients were retrospectively reviewed on the hospital information record system. Data including demographic data, seasonal application frequency, complete blood count results and clinical findings were recorded. Autoimmune, inflammatory, polyradiculopathy, rheumatologic disease, pregnancy, traumatic epistaxis, oncologic-hematologic patients, patients with a history of hypertension, chemotherapy patients, structural disorders in nasal examination and age above 18 years old were accepted as exclusion criteria. The patients were categorized into three groups which are recurrent epistaxis, non-current epistaxis groups and control group consisted of healthy patients who came for routine control with similar age and demographic characteristics.

\section{STATISTICAL ANALYSIS}

Standard deviation and mean values were calculated for continuous variables, and median and interquartile range of the non-parametric data were calculated. Each of the independent variables was subjected to chi-square test and compared. Multivariate logistic regression analysis was performed to understand the effects of the statistically significant independent variables on recurrent epistaxis. The descriptive statistical analysis of all variables was carried out using SPSS 18.0.

\section{RESULTS}

The study group was composed of 143 patients (73 recurrent and 70 non-recurrent) and 77 healthy individuals. Of 73 patients in the recurrent epistaxis group, 52 (71.2\%) are male, $21(28.8 \%)$ are female. The non-recurrent epistaxis group involved $44(62.8 \%)$ males, $26(37.2 \%)$ females. Of 77 patients in the control group, $52(67.5 \%)$ are male, 25 (32.5\%) are female. As for the seasonal prevalence, epistaxis was observed frequently in winter, but its seasonal prevalence did not differ between the recurrent and non-recurrent groups $(\mathrm{P}=0.542)$. There was no statistically significant difference in the mean age and sex distribution between the epistaxis groups (recurrent and non-recurrent) and the control group. The demographic characteristics of the patients are shown in

\section{Table 1.}

Regarding the CBC parameters, the MPV value was significantly higher in the recurrent epistaxis group than in the non-recurrent epistaxis group $(8.91 \pm 1.16,8.48 \pm 1.06 ; \mathrm{P}=$ 0.006, respectively) (Table 1, Figure 1). Non-recurrent 
The recurrence of epistaxis with simple blood tests

Table 1. Comparison of demographic and laboratory parameters between groups

\begin{tabular}{|c|c|c|c|c|c|c|}
\hline & $\begin{array}{l}\text { Recurrent epistaxis group } \\
\qquad \mathrm{n}=73\end{array}$ & $\begin{array}{l}\text { Non recurrent epistaxis Group } \\
\qquad \mathrm{n}=\mathbf{7 0}\end{array}$ & $\begin{array}{c}\text { Control Group } \\
\mathrm{n}=77\end{array}$ & p1 & p2 & p3 \\
\hline Age (years) & $49.31 \pm 19.96$ & $43.72 \pm 22.35$ & $40 \pm 24.12$ & 0.103 & 0.054 & 0.239 \\
\hline Gender (female/male) & $21 / 52$ & $26 / 44$ & $25 / 52$ & & & \\
\hline Seasons (n;\%) & & & & 0.542 & & \\
\hline Winter & $31(42.5)$ & $30(42.9)$ & & & & \\
\hline Spring & $12(16.4)$ & $16(22.9)$ & & & & \\
\hline Summer & $11(15.1)$ & $12(17.1)$ & & & & \\
\hline Autumn & $19(26)$ & $12(17.1)$ & & & & \\
\hline \multicolumn{7}{|l|}{ Laboratory findings } \\
\hline $\mathrm{WBC}\left(\times 10^{3} / \mathrm{mm}^{3}\right)$ & $10.04 \pm 3.63$ & $9.98 \pm 3.84$ & $8.17 \pm 2.15$ & 0.629 & $<0.001$ & 0.239 \\
\hline Neutrophil $\left(\times 10^{3} / \mathrm{mm}^{3}\right)$ & $6.13 \pm 2.51$ & $6.08 \pm 2.56$ & $4.55 \pm 1.68$ & 0.604 & $<0.001$ & 0.002 \\
\hline Lymphocytes $\left(\times 10^{3} / \mathrm{mm}^{3}\right)$ & $2.51 \pm 0.97$ & $2.6 \pm 1.01$ & $2.67 \pm 0.97$ & 0.531 & 0.242 & 0.563 \\
\hline Platelets $\left(\times 10^{3} / \mathrm{mm}^{3}\right)$ & $251.43 \pm 109.79$ & $285.78 \pm 100.87$ & $255.74 \pm 58.76$ & 0.034 & 0.25 & 0.129 \\
\hline Monocytes $\left(\times 10^{3} / \mathrm{mm}^{3}\right)$ & $1.17 \pm 2.75$ & $0.99 \pm 2.37$ & $0.65 \pm 0.33$ & 0.428 & 0.019 & 0.121 \\
\hline Eosinophils $\left(\times 10^{3} / \mathrm{mm}^{3}\right)$ & $0.18 \pm 0.12$ & $0.21 \pm 0.15$ & $0.24 \pm 0.26$ & 0.232 & 0.706 & 0.544 \\
\hline Basophil $\left(\times 10^{3} / \mathrm{mm}^{3}\right)$ & $0.07 \pm 0.09$ & $0.06 \pm 0.08$ & $0.05 \pm 0.09$ & 0.412 & 0.043 & 0.199 \\
\hline NLR & $2.91 \pm 2.07$ & $2.62 \pm 1.46$ & $1.95 \pm 1.18$ & 0.527 & $<0.001$ & 0.002 \\
\hline PLR & $113.44 \pm 63.98$ & $120.51 \pm 55.36$ & $106.04 \pm 41.02$ & 0.138 & 0.951 & 0.046 \\
\hline LMR & $3.67 \pm 1.68$ & $3.93 \pm 1.88$ & $5.7 \pm 5.01$ & 0.826 & 0.012 & 0.028 \\
\hline Hemoglobin g/dL & $12.55 \pm 2.37$ & $12.55 \pm 2.13$ & $12.85 \pm 2.06$ & 0.841 & 0.554 & 0.38 \\
\hline HCT \% & $38.36 \pm 6.74$ & $38.28 \pm 5.67$ & $38.86 \pm 5.52$ & 0.713 & 0.864 & 0.458 \\
\hline$\overline{M C V} \mathrm{fL}$ & $85.82 \pm 7.25$ & $83.86 \pm 10.46$ & $84.02 \pm 12.01$ & 0.271 & 0.509 & 0.624 \\
\hline $\mathrm{MCH}$ pg & $27.93 \pm 3.01$ & $27.88 \pm 3.49$ & $27.91 \pm 3.52$ & 0.814 & 0.987 & 0.899 \\
\hline $\mathrm{MCHC} g / \mathrm{dL}$ & $32.67 \pm 1.33$ & $32.7 \pm 1.29$ & $32.49 \pm 1.26$ & 0.394 & 0.519 & 0.215 \\
\hline RDW \% & $14.9 \pm 1.94$ & $15.13 \pm 2.73$ & $13.52 \pm 1.03$ & 0.838 & $<0.001$ & $<0.001$ \\
\hline MPV fL & $8.91 \pm 1.16$ & $8.48 \pm 1.06$ & $8.58 \pm 0.09$ & 0.006 & 0.051 & 0.346 \\
\hline PCT \% & $0.21 \pm 0.08$ & $0.24 \pm 0.07$ & $0.21 \pm 0.04$ & 0.043 & 0.793 & 0.024 \\
\hline PDW \% & $16.54 \pm 1.81$ & $16.33 \pm 1.52$ & $15.38 \pm 2.72$ & 0.052 & $<0.001$ & 0.005 \\
\hline $\begin{array}{l}\text { p1 = comparison between } \\
\text { p2 = comparison between } \\
\text { p3 = comparison between } \\
\text { (NLR: neutrophil-to-lymph } \\
\text { Hematocrit; MCV: mean ce } \\
\text { Mean platelet volume; PCT }\end{array}$ & $\begin{array}{l}\text { nt epistaxis group and non-r } \\
\text { nt epistaxis group and the } c c \\
\text { current epistaxis group and c } \\
\text { atio; PLR: platelet-to-lympho } \\
\text { ne; MCH: mean cell hemoglc } \\
\text { crit; PDW: Platelet distributic }\end{array}$ & $\begin{array}{l}\text { urrent epistaxis (Group1-2) } \\
\text { rol group (Group1-3) } \\
\text { trol group (Group2-3) } \\
\text { e ratio ; MPV: mean platelet volu } \\
\text {; MCHC: mean cell hemoglobin c } \\
\text { width SD: standard deviation ) }\end{array}$ & $\begin{array}{l}\text { LMR: Lymphocyt } \\
\text { entration; RDW: }\end{array}$ & $\begin{array}{l}\text { nonocy } \\
\text { d cell dis }\end{array}$ & $\begin{array}{l}\text { atio; } \mathrm{HC} \\
\text { bution w }\end{array}$ & th; MPV: \\
\hline
\end{tabular}

epistaxis group's mean platelet and platelet (PCT) values were significantly higher compared to the recurrent epistaxis group ( $\mathrm{P}=0.034, \mathrm{P}=0.043$, respectively). Mean leukocyte (WBC), monocyte and basophil values of the recurrent epistaxis patients were significantly higher than control group $(\mathrm{P}<0.05)$. Furthermore, the mean neutrophil, neutrophil-lymphocyte ratio (NLR) and RDW and platelet distribution width (PDW) values were significantly higher in the epistaxis groups than in the control group. Nevertheless, the mean lymphocyte-monocyte ratio (LMR) was significantly higher in control group compared to epistaxis groups. In addition, control group mean platelet-lymphocyte ratio (PLR) and PCT values were significantly lower compared to the non-recurrent epistaxis group. There were no statistically significant relationships between other variables (Table 1). The multivariate regression analysis was performed. Age, gender, MPV, RDW, PCT, platelet, NLR, PLR and LMR were analyzed for determine these parameters
Table 2. Multivariate logistic regression analysis of different variables for recurrent epistaxis

\begin{tabular}{lccc}
\hline Variables & Wald & Odds ratio & $\mathbf{P}$ \\
\hline Age & 0.882 & $1.009(0.991-1.026)$ & 0.348 \\
\hline Gender & 2.136 & $0.568(0.266-1.213)$ & 0.144 \\
\hline MPV fL & 2.87 & $1.367(0.952-1.963)$ & 0.028 \\
\hline RDW & 4.68 & $0.967(0.836-1.119)$ & 0.655 \\
\hline PCT \% & 3.614 & $0.011(0.001-1.149)$ & 0.057 \\
\hline Platelet count $\left(\times 10^{3} / \mathrm{mm}^{3}\right)$ & 0.179 & $0.999(0.994-1.004)$ & 0.673 \\
\hline NLR & 0.913 & $1.16(0.855-1.573)$ & 0.339 \\
\hline PLR & 0.18 & $0.998(0.988-1.008)$ & 0.671 \\
\hline LMR & 0.003 & $1.007(0.793-1.279)$ & 0.954 \\
\hline
\end{tabular}

on recurrent epistaxis. High MPV value was found to increase epistaxis 1.367 times (OR: 1.367 [\% 95 CI: 0.9521.963]) (Table 2). 


\section{DISCUSSION}

Epistaxis is a common condition that rarely requires applying to ED. Certain patient groups can apply to emergency rooms for recurrent epistaxis $[11,12]$. Various demographic and risk factors have been described for simple epistaxis events in the literature $[12,13]$. However, which risk factors are in play for recurrent epistaxis is yet to be fully clarified. Two recent studies reported that the risks factors recognized at the very beginning were not associated with recurrent epistaxis [14,15]. We examined in this study whether there is a relationship between simple complete blood count parameters and recurrent epistaxis. Our study showed that high MPV value increased epistaxis 1.367 times (OR: 1.367 [\% 95 CI: 0.952-1.963]) and believe that high MPV value can predict recurrent epistaxis.

MPV is one of the most important parameters routinely taken from many patients that show the function and activity of platelet. The relationship between MPV and bleeding time has been shown by several studies [16]. Studies emphasized that large platelet size and granular and secretion capacity were related, and moreover, increased MPV led to an increase in secretive capacities of thromboxane A2, platelet factor 4 and thromboglobulin $[17,18]$. Increased MPV values have been found related to myocardial infarctus, coronary failure, stroke and hypertension [19-21]. Goel et al. [22] argued an independent relationship between increased MPV value and ischemic stroke. In a recent study, they reported that MPV might play a predictive role for acute bronchiolitis diagnosis and that MPV's predictive role was better than other inflammatory parameters [23]. Bath et al. found the increase in MPV value to be leading a positively correlational increase in embolic risk [24]. In another study, Karabulut et al. [3] stated that there was a relationship between decreased MPV values and recurrent epistaxis and emphasized that it might be due to the positive correlation between MPV size and platelet. However, our study found high MPV levels caused an increase in the bleeding tendency in the patients with recurrent epistaxis., and it does not coincide with the theory that large platelets are associated with better hemostasis $[19,25]$.

RDW shows changes in the size of red blood cells and is often used to diagnose anemia and shows the heterogeneity of erythrocytes [7]. Studies have shown that RDW is related to vascular events. In one of these studies, it was stated that RDW might be useful in predicting the severity and functional results of stroke in stroke patients having symptoms for $<24$ hours [26]. In another study, RDW was significantly associated with cardiovascular disease-related deaths in atherosclerosis patients [27]. Goyal et al. [28] stated that RDW is associated with several gastrointestinal disease such as celiac, colon cancer, hepatitis and pancreatitis. Another study found RDW levels to be significantly higher in patients with retinal venous occlusion than in the control group [29]. Kemal et al. [30] found risk of recurrent epistaxis to be higher in patients with low RDW levels than in the normal population. Although RDW level was higher both in the recurrent and non-recurrent groups than in the control group, no significant difference was found between the recurrent and non-recurrent patients $(\mathrm{P}=0.838)$.

Recently, WBC subtypes (NLR, PLR and LMR) have been used as an indicator of systemic inflammatory response [31,32]. In their study, Aksakal et al. [33] found no relationship between NLR and recurrent epistaxis but higher PLR values in the epistaxis group. In our study, no significant relationship was observed between NLR, PLR and LMR and recurrent epistaxis $(\mathrm{P}>0.05)$.

There were some limitations to this study. Firstly, our study was retrospectively conducted in a monocenter manner and with few patients. Secondly, the fact that comorbid diseases which might be related to epistaxis and the possible relationship between the medication used and the epistaxis were not included in the study is the most important limitation. Thirdly, parameters of patients' blood only taken at the moment of application were examined, and it was not possible to compare the basal and subsequent blood parameter values. The fact that these parameters were not compared with acute phase reactants such as CRP and sedimentation which are commonly used is an important limitation. Given the retrospective design of our study, our results need to be confirmed by prospective studies with new hypotheses.

\section{CONCLUSION}

High levels of MPV caused an increase in the bleeding tendency in the patients with recurrent epistaxis. In consideration of its unknown mechanism, it would be appropriate to refer these patients for the evaluation of etiological causes.

Declaration of interest: The authors report no conflicts of interest.

Financial Disclosure: No financial support was received.

\section{REFERENCES}

1. Addison A, Paul C, Kuo R, Lamyman A, MartinezDevesa P, Hettige R. Recurrent epistaxis: predicting risk of 30-day readmission, derivation and validation of RHINO-ooze score. Rhinology. 2017;55:99-105.

2. Chaaban MR, Zhang D, Resto V, Goodwin JS. Factors influencing recurrent emergency department visits for epistaxis in the elderly. Auris Nasus Larynx. 2018;4:7604.

3. Karabulut AE, Çevik Y, Emektar E, Çorbacioğlu ŞK, Dağar S, Yardim O. Analysis of mean platelet volume and red blood cell distribution width in recurrent epistaxis. Turk J Emerg Med. 2018;18:67-70.

4. Adoga AA, Kokong DD, Mugu JG, Okwori ET, Yaro JP. Epistaxis: The demographics, etiology, management, and predictors of outcome in Jos, North-Central Nigeria. Ann Afr Med. 2019;18:75-9. 
5. Kovács S, Csiki Z, Zsóri KS, Bereczky Z, Shemirani AH. Characteristics of platelet count and size and diagnostic accuracy of mean platelet volume in patients with venous thromboembolism. A systematic review and meta-analysis. Platelets. 2019;30:139-47.

6. Patti G, Di Martino G, Ricci F, et al. Platelet Indices and Risk of Death and Cardiovascular Events: Results from a Large Population-Based Cohort Study.Thromb Haemost. 2019;119:1773-84.

7. Zhang Q, Cao X, Zhou J, et al. Red cell distribution width reflects the early stage residual renal function in peritoneal dialysis patients. Saudi J Kidney Dis Transpl. 2018;29:1082.

8. Huang YL, Han ZJ, Hu ZD. Red blood cell distribution width and neutrophil to lymphocyte ratio are associated with outcomes of adult subarachnoid haemorrhage patients admitted to intensive care unit. Ann Clin Biochem. 2017;54:696-701.

9. Ćatić J, Jurin I, Lucijanić M, Jerkić H, Blažeković R. High red cell distribution width at the time of ST segment elevation myocardial infarction is better at predicting diastolic than systolic left ventricular dysfunction: A single-center prospective cohort study. Medicine. 2018;97:601.

10. Lam M, Roszik J, Kanikarla-Marie P, et al. The potential role of platelets in the consensus molecular subtypes of colorectal cancer. Cancer Metastasis Rev. 2017;36:27388.

11. Cooper SE, Ramakrishnan VR. Direct cauterization of the nasal septal artery for epistaxis. Laryngoscope. 2012;122:738-40.

12. Pallin DJ, Chng YM, McKay MP, Emond JA, Pelletier AJ, Camargo Jr CA. Epidemiology of epistaxis in US emergency departments, 1992 to 2001. Ann Emerg Med. 2005;46:77-81.

13. Chaaban MR, Zhang D, Resto V, Goodwin JS. Demographic, seasonal, and geographic differences in emergency department visits for epistaxis. Otolaryngol Head Neck Surg. 2017;156:81-6.

14. Abrich V, Brozek A, Boyle TR, Chyou PH, Yale SH. Risk factors for recurrent spontaneous epistaxis. Mayo Clin Proc. 2014;89:1636-43.

15. Ando Y, Iimura J, Arai S, et al. Risk factors for recurrent epistaxis: importance of initial treatment. Auris Nasus Larynx. 2014;41:41-5.

16. Bohec P, Gachelin J, Ollivier V, et al. Acoustophoretic purification of platelets: Feasibility and impact on platelet activation and function. Platelets. 2019;30:17480.

17. Ju HY, Kim JK, Hur SM, et al. Could mean platelet volume be a promising biomarker of progression of chronic kidney disease? Platelets. 2015;26:143-7.
18. Sansanayudh N, Muntham D, Yamwong S, Sritara P, Akrawichien T, Thakkinstian A. The association between mean platelet volume and cardiovascular risk factors. Eur. J. Intern. Med. 2016;30:37-42.

19. Liu X, Wang S, Yuan L, et al. Increased Mean Platelet Volume is Associated with Higher In-Hospital Mortality Rate in Patients with Acute Myocardial Infarction. Clin Lab. 2017;63:163-7.

20. Chu S, Becker R, Berger P, et al. Mean platelet volume as a predictor of cardiovascular risk: a systematic review and meta-analysis. Thromb Haemost. 2010;8:148-56.

21. Budak YU, Huysal K, Demirci H. Correlation between mean platelet volume and B-type natriuretic peptide concentration in emergency patients with heart failure. Biochem Med. 2015;25:97-102.

22. Goel A, Saini S, Moinuddin A, et al. Mean platelet volume and mean platelet volume/platelet count ratio commensurate to severity in ischemic stroke. Int J Neurosci. 2018;6:6-10.

23. Gokce S, Kurugol Z, Suner A. The role of mean platelet volume in the early detection of acute bronchiolitis: A prospective study. Clin Respir J. 2018;12:2513-8.

24. Bath P, Algert C, Chapman N, Neal B. Association of mean platelet volume with risk of stroke among 3134 individuals with history of cerebrovascular disease. Stroke. 2004;35:622-6.

25. Vizioli L, Muscari S, Muscari A. The relationship of mean platelet volume with the risk and prognosis of cardiovascular diseases. Int J Clin Pract. 2009;63:150915.

26. Kara H, Degirmenci S, Bayir A, et al. Red cell distribution width and neurological scoring systems in acute stroke patients. Neuropsychiatr Dis Treat. 2015;11:733.

27. Wonnerth A, Krychtiuk KA, Mayer FJ, et al. Red cell distribution width and mortality in carotid atherosclerosis. Eur J Clin Invest. 2016;46:198-204.

28. Goyal H, Lippi G, Altin Gjymishka BJ, Chhabra R, May E. Prognostic significance of red blood cell distribution width in gastrointestinal disorders. World J Gastroenterol. 2017;23:4879.

29. Ozkok A, Nesmith BL, Schaal S. Association of Red Cell Distribution Width Values with Vision Potential in Retinal Vein Occlusion. Ophthalmol Retina. 2018;2:5826.

30. Kemal O, Müderris T, Sevil E, Kutlar G. Relation of mean platelet volume and red blood cell distribution width with epistaxis. Laryngoscope. 2015;125:788-90.

31. Qin B, Ma N, Tang Q, et al. Neutrophil to lymphocyte ratio (NLR) and platelet to lymphocyte ratio (PLR) were useful markers in assessment of inflammatory response and disease activity in SLE patients. Mod Rheumatol. 2016;26:372-6. 
32. Kim DS, Shin D, Lee MS, et al. Assessments of neutrophil to lymphocyte ratio and platelet to lymphocyte ratio in Korean patients with psoriasis vulgaris and psoriatic arthritis. J Dermatol. 2016;43:30510.
33. Aksakal C, Şahin M. Evaluation of neutrophil/lymphocyte ratio and platelet/lymphocyte ratio in recurrent epistaxis in childhood: case controlled study. Pan Afr Med J. 2019;32:154. 